\title{
Sedentary work in middle life and fracture of the proximal femur
}

\author{
C Cooper ${ }^{\star}, \mathrm{C}$ Wickham, D Coggon
}

Hip fractures in the elderly are a major public health problem. ${ }^{1}$ Their incidence is associated with osteoporosis and a tendency to fall, ${ }^{2}$ both of which may be increased by physical inactivity. Before the age of 65, occupation is a major determinant of total physical activity. To examine the influence of work on later risk of hip fracture, we have compared occupational activity at age 50 in a series of elderly men and women with hip fractures and in controls selected from the same community.

\section{Method}

The case group comprised 300 patients ( 60 men and 240 women) aged 50 and over who were admitted sequentially to an orthopaedic unit with fracture of the proximal femur and who could pass an abbreviated mental test. ${ }^{3}$ Each case was matched with two controls of the same sex and age to within four years. The controls were selected from a list of all residents of the health district served by the orthopaedic unit who were registered with the National Health Service. They too had to pass a mental test.

Each case-control set was visited by one of three trained interviewers. Cases were interviewed in hospital within ten days of admission. Controls were interviewed at home within three months of their matched case $(68 \%)$ or during the corresponding quarter a year later $(32 \%)$.

At interview subjects were asked their occupation at age 50 . Job titles were then graded by an occupational epidemiologist (DC) according to the proportion of the working day that individuals were likely to have spent sitting. This assessment was carried out blind to whether subjects were cases or controls. Three levels were distinguished: sedentary, intermediate, and weight bearing. Table 1 gives examples of the most common jobs in each category.

Other potential risk factors recorded at interview included body weight and height, cigarette smoking, alcohol consumption, age at menopause, and history

^Present address: Rheumatology Unit, Department of Medicine, Bristol Royal Infirmary, Bristol BS2 8HW.

MRC Environmental Epidemiology Unit, University of Southampton, Southampton General Hospital, Southampton SO9 4XY

C Cooper, C Wickham, D Coggon of oestrogen treatment. Grip strength in each hand was assessed using an isometric dynamometer.

Comparisons between cases and controls were by conditional logistic regression for matched sets. ${ }^{4}$ The relation between grip strength and occupational grade was examined by an analysis of covariance.

\section{Results}

The ages of the cases ranged from 50 to 99 with median 79 . To obtain the required 600 controls it was necessary to approach 889 subjects. The reasons for the incomplete response were death or change of address (73), failure of mental test (65), and refusal (151).

Table 2 shows the risk of hip fracture in relation to occupational activity at age 50 . In both men and women the risk of fracture was greatly increased in sedentary occupations. This effect remained when women who described themselves as housewives were excluded from the analysis and also after allowance for the possible confounding effects of body mass index, cigarette smoking, alcohol consumption, age at menopause, and oestrogen treatment.

After allowance for age and sex, current grip strength was positively associated with occupational activity at age 50 in both cases and controls. The trend was statistically significant $(p=0.01)$ in controls.

\section{Discussion}

The results of this study suggest that sedentary work in middle age predisposes to hip fracture in later life.

Table 1 Grading of occupations according to the proportion of the working day spent sitting. The occupations listed are the most frequent in each category

\begin{tabular}{lll}
\hline Sedentary & Intermediate & Weight bearing \\
\hline Accountant & Housewife & Barmaid \\
Cashier & Children's nanny & Builder \\
Civil servant & Florist & Cleaner \\
Clerk & Housekeeper & Factory labourer \\
Company director & Manager & Farm labourer \\
Driver & Pharmacist & Fitter \\
Receptionist & School matron & Nurse \\
Secretary & Storeman & Railwayman \\
Stockbroker & Teacher & Salesman \\
Surveyor/architect & Watchman & Seaman \\
\hline
\end{tabular}


Table 2 Risk of hip fracture by occupational grade

\begin{tabular}{|c|c|c|c|c|c|}
\hline \multirow[b]{2}{*}{ Sex } & \multirow[b]{2}{*}{ Occupational grade } & \multicolumn{2}{|l|}{ No of } & \multirow{2}{*}{$\begin{array}{l}\text { Unadjusted } \\
\text { relative risk }\end{array}$} & \multirow{2}{*}{$\begin{array}{l}\text { Adjusted relative risk } \\
\text { (with } 95 \% \text { confidence interval })^{\star}\end{array}$} \\
\hline & & Cases & Controls & & \\
\hline $\begin{array}{l}\text { Women } \\
\text { (excluding } \\
\text { housewives) }\end{array}$ & $\begin{array}{l}\text { Sedentary } \\
\text { Intermediate } \\
\text { Weight bearing }\end{array}$ & $\begin{array}{l}30 \\
13 \\
49\end{array}$ & $\begin{array}{r}19 \\
61 \\
136\end{array}$ & $\begin{array}{l}7 \cdot 1 \\
1 \cdot 0 \\
1 \cdot 7\end{array}$ & $\begin{array}{l}5.9(0.9-38 \cdot 1) \\
1.0 \\
2.6(0.5-12.5)\end{array}$ \\
\hline Men & $\begin{array}{l}\text { Sedentary } \\
\text { Intermediate } \\
\text { Weight bearing }\end{array}$ & $\begin{array}{r}21 \\
5 \\
33\end{array}$ & $\begin{array}{l}18 \\
30 \\
72\end{array}$ & $\begin{array}{l}4 \cdot 8 \\
1 \cdot 0 \\
2 \cdot 2\end{array}$ & $\begin{array}{l}3.6(1 \cdot 0-13 \cdot 1) \\
1.0- \\
1.5(0.5-4 \cdot 5)\end{array}$ \\
\hline
\end{tabular}

^Adjusted for body mass index, cigarette smoking, alcohol consumption and, in women, age at menopause and oestrogen treatment.

The association could not be explained by a confounding effect of body mass index, cigarette smoking, alcohol consumption, age at menopause, or oestrogen treatment.

The activities important to skeletal health are those that involve weight bearing and muscle loading. ${ }^{5} \mathrm{We}$ therefore graded occupations according to time spent sitting rather than by energy expenditure. The assignment of activity levels was liable to error both from inaccuracies in subjects' recall and also from the uncertainties that arose when job descriptions were not sufficiently specific. Nevertheless, we would expect the occurrence of such errors to be similar in cases and controls and as such it would tend to obscure rather than exaggerate associations with fracture.

Our findings accord with those of Boyce and Vessey who have reported a significant association between physical inactivity in middle age and the risk of later hip fracture. ${ }^{6}$ In their study, however, the assessment of activity depended more on leisure pursuits than on occupation. Moreover, it is not clear by what criteria they graded occupational activity.

Sedentary work could influence the later risk of hip fracture in at least two ways. Firstly, it might accelerate the development of osteoporosis. Mechanical stimuli are important to the maintenance of skeletal mass and physical inactivity is an established cause of osteoporosis. ${ }^{7}$ Secondly, sedentary occupations might predispose to muscle weakness and poor neuromuscular function in later years, thereby increasing the frequency of falls. ${ }^{8}$ Our finding of an association between occupational grade and current grip strength is consistent with this idea.

We conclude that sedentary occupations at around the age of 50 are associated with an increased risk of hip fracture in elderly people. Over the past 50 years sedentary work has become more common. This trend may have contributed to the steep rise in the incidence of hip fracture over the same period.

1 Royal College of Physicians. Fractured neck of femur: prevention and management. London: Royal College of Physicians, 1989.

2 Cooper C, Barker DJP, Morris J, Briggs RSJ. Osteoporosis, falls and age in fracture of the proximal femur. $\mathrm{Br} \mathrm{Med}$ 1987;295:13-5.

3 Quereshi KN, Hodkinson HM. Evaluation of a ten question mental test in the institutionalised elderly. Age Ageing 1974; 3:152-7.

4 Breslow NE, Day NE. Conditional logistic regression for matched sets. In: Breslow NE, Day NE, eds. Statistical methods in cancer research. Vol 1. The analysis of case control studies. Lyon: International Agency for Research on Cancer, 1980:248-79.

5 Siscovick DS, LaPorte RE, Newman JM. The disease-specific benefits and risks of physical activity and exercise. Public Health Rep 1985;100:180-8.

6 Boyce WJ, Vessey MP. Habitual physical inertia and other factors in relation to risk of fracture of the proximal femur. Age Ageing 1988;17:319-27.

7 Smith R. Exercise and osteoporosis. Br Med J 1985;290:1163-4.

8 Wickham C, Cooper C, Margetts BM, Barker DJP. Muscle strength, activity, housing and the risk of falls in the elderly. Age Ageing 1989;18:47-51.

Accepted 13 March 1989 